\title{
Gender Discrimination in assigning Dull or Challenging Tasks in Banking Sector of Pakistan
}

\author{
Basheer Ahmad Samim ${ }^{1}$ and Nadiya Rashid ${ }^{2 *}$
}

\begin{abstract}
This study investigates the gender biases of managers in assigning tasks to subordinates. Gender discrimination affects the productivity and efficiency of employees in any organization. It is assumed that managers assign challenging tasks to subordinates of same gender and assign dull tasks to the subordinate of opposite gender. The industry taken for the research purpose was banking sector of Pakistan. Ten banks and ten branches of each bank were taken for this study. The data was taken from the managers and four subordinates, which summed up to 100 managers and 400 subordinates; the questionnaire was comprised of demographics and personality traits. The model illustrated that managers commit gender discrimination in assigning a dull/challenging task to a subordinate. Generalized Linear Model (Logistic Regression) was used to study a nominal variable task type with two levels Challenging Task (1) and Dull Task (0). Young male managers were found to follow exchange theory concept. Experienced, male managers were mostly found to assign challenging tasks to the subordinate of opposite gender and dull task to the subordinate of same gender.
\end{abstract}

Keywords: Gender discrimination, challenging tasks in banking sector

\section{Introduction}

Employees in banking sector of Pakistan thinks that the managers commit gender discrimination in assigning the dull and challenging task to their subordinates. This study aims to investigate the gender discriminating behavior of managers regarding the assignment of task. The question is what kind of managers, male or female, commit gender discrimination and which gender is suffering by such behavior? Four different combinations (Male Manager \& Male Sub-ordinate, Male Manager \& Female Sub-ordinate, Female Manager \& Male Sub-ordinate, and Female Manager \& Female Sub-ordinate) are intended to be compared regarding the assignment of task. This study will help to identify the

Author's Affiliation:

$\begin{array}{lll}\text { Institution(s) Name: } & { }^{1} \text { Iqra University, } & { }^{2} \text { Iqra University } \\ \text { Country: } & { }^{1} \text { Pakistan, } & { }^{2} \text { Pakistan }\end{array}$

Corresponding Author's Email: 1drbasheer@iqraisb.edu.pk

* The material presented by the author does not necessarily portray the view point of the editors/ editorial board and the management of ORIC, Iqra University, Main Campus, Karachi-PAKISTAN. 
combinations of manager and sub-ordinate having different inclination in assigning the task with different difficulty level.

\section{Literature Review}

The labor market is the vital instrument by which an economy can get the advantages of growth and this advantage can be dispersed to the poor and underprivileged group. Every person, male or female, must have right to enter in labor market and to do decent work. If everyone performs according to the required standards, irrespective of gender, then gender disparity would surely be reduced. For economic growth, decent work for women is a prerequisite because in the extended period all the resources in the economy should be tapped to make the resources utilization optimal. Lehmijoki and Palokangas (2006) found positive relationship among risk of population growth, internal disagreement, and gender discrimination. They find that gender discrimination is very common in developing countries. Different researchers have different views about gender discrimination. Gender inequity is about treating the two genders unequally and it is against the ethics. It goes against a person's self esteem and independence and is also against the societal rights of a person. Both the genders have different perceptions regarding gender inequity and this might be the result of their previous experience, the society in which they are living, or inborn nature (Ngo, Foley, Wong \& Loi, 2003).

Aspects of gender discrimination in a workplace are studied by Barclay (1982), in which he applied social learning theory to explain gender discrimination. According to him, it is essential to study the dysfunctional feature of the expectancy learning which could result in agony, depression and frustration. This expectancy learning can be found in both men and women related to gender discrimination. If a person is satisfied with a job then he/she makes valuable contributions towards the organization and if he/she lacks job satisfaction than they cannot be productive for the organization. Rosen and Jerdee (1978) studied the perceptions of male managers about the sex differences and only male managers are the part of this study. They use four scales to measure sex differences. The first is aptitude, knowledge and skill, the second is interest and motivation, the third is temperament and the last one is work habits and attitude .Their study concludes that male managers mostly favor male for promotions and employment.

Renwick and Tosi (1978) mentioned in their study that when evaluation is done for selection more preference is given to such factors like ability and interpersonal skills for male and for female factors such as education and appearance are given importance for female. They conducted the study to assess the role of academic qualifications and demographic variables regarding the selection decision. They find that academic qualification of a candidate is more significant in making a selection decision than the marital status and gender of candidate. While selecting the candidate, if the decision maker only has the information about the gender of the candidate then the decision is effected by sex-role stereotypes because that is the only on hand information for decision making. If other information like the education of the candidate is available then the impact of stereotyping is reduced. According to them, many researches done on sex-role stereotyping doesn't include educational qualifications in their studies and as sufficient information is not provided to decision maker than the researchers are left with only one option that is to make the decision based on sexrole stereotypes and this is the reason that decision maker makes their decision in favor of male than female. It is also assumed that women are more committed towards the family responsibilities as compared to career and women give priority to their home first which is also one of the reasons for preferring male over females.

Sex discrimination takes place as a result of manager-client relationships; the basis of rational bias theory (Szwajkowski \& Larwood, 1991). The discrimination is more expected in 
relationships, where the client is comparatively important to the manager and is less likely to happen, in the presence of conditions indicating that the client condemns discrimination. Haberfeld(1992) argued that in assessing gender discrimination in an organization it is important to consider organizational variables rather than just focusing in individual variables such as education, experience because in order to study wage difference between male and female, it is important to include organizational variables such as job, position, department etc in the study.

In comparing the two genders, women believe that they are more discriminated as compared to male and not only women think this but generally both the genders have the perception that males are favored more over females. As a result if women feel that they will not be evaluated fairly, and they will be given less ratings then women will not put all the hard work in the jobs and will eventually perform badly. These senses of discrimination make women feel that they are helpless (Ngo, Foley, Wong \& Loi, 2003). It also lowers down the efficacy expectations which may result in negative consequence among females (Barclay, 1982). Igbaria and Baroudi (1995) found that in terms of career advancement men are preferred over women regarding promotions.

Stereotyping is the procedure in which classification of a person is done to a specific group and they are assigned certain characteristics based on the association of the person to that group. If an individual is indulged in doing stereotyping, based on gender, then a person allocates certain characteristics to that person based on gender (Bartol, 1980). Stereotyping is basically a classification process, and one of the reasons to do stereotyping is that it is like a work-saving instrument to make things easier and sort out the multifaceted world we come across. The dilemma is that stereotypes for a particular group are mostly incorrect and generalizations made for that group, in reality, may not be applicable to that group. In such conditions, stereotype becomes the main cause of inaccurate reasoning. This results in prejudiced feelings and proceedings for an individual. It is because of a person's association with that group and not because of an individual's personal attributes in real terms, which may result in favor or against of a person. Heilman (1997) generally found that in conducting research on perception it does not matter as what academic qualifications participants have or to what social class or religion they belong to or which age or marital status they have; they all show immense agreement in the attributing characteristics to male or female. Stereotyping is very common and is reported by many researchers. Stereotyping does not always have negative aspect, it can be positive for either of the gender, but it is harmful for the disadvantage group. The disadvantage of stereotyping is that the whole group is assigned certain characteristics and individual characteristics and qualities of a person are ignored (Lane \& Crane, 2002).

Women are given less salaries, less reward; their working conditions are different as compared to men. Women are not given challenging tasks as well (Ngo, Foley, Wong \& Loi, 2003). "Think Manager-Think Male" is a global phenomenon and globalization of management has made it very important. Though, proportion of working women has improved in past years but still male are considered to have those characteristics which a managerial position require. As a result women are discriminated in all fields of job whether recruitment and selection, training and development, or promotions (Schein, Muller, Lituchy \& Liu, 1996).

If the supervisor belongs to some ethnic group of employees, then there is a strong tendency that the supervisor supports the group members without considering their competencies. In such a situation, some competent employees are ignored along with the women community as women are not usually considered to be part of such a group. Men are normally placed at primary jobs; the jobs that help them to grow and reach at the top level 
management and women are given secondary jobs; the jobs that are of low level and are not much helpful in the career advancement (Igbaria and Baroudi, 1995).

A potential entrant may get an advantage over other entrants in terms of getting a demanding task in the initial phase of career, but it does not always. New managers who get the challenging task when they join any organization exhibit enhanced performance as compared to those new managers who are not given challenging task. If a manager assumes that the task given to him/her is challenging then he/she shows improved performance rather than those who think that the task given to them is an easy and routine task (Berlew \& Hall, 1966).

At initial placement, males are preferred over females for more challenging positions. Females are preferred for less challenging positions as a result there will be less scope for them to reach at the upper level of management. Male employees who work with females at good positions exhibit less tendency of doing discrimination against women and consider them for challenging positions in initial placement as compared to males who work with males at high positions. The results of the study according to them are both negative and positive. The negative aspect is that though there are social and legal laws and regulations but when it comes to make decisions regarding placement of women after getting job, mostly females are selected for dull positions both by male managers as well as by female managers. The positive aspect is that if already females are working at good positions in an organization, then because of experience of working with females, managers do less discrimination and it reduces the probability of assigning unchallenging task future hiring (Taylor \& Ilgen, 1981).

Mai-Dalton and Sullivan (1981) conducted an experiment in which subjects were given the choice to assign an interesting and rewarding task or an uninteresting and unrewarding task to either a male or female. College students and banking executive of both genders were taken as participants. A scenario was given to each participant along with a 2 page questionnaire. The scenario was that the participants had to consider themselves as branch manager of a bank in which they had at least two female and two male sub-ordinates and out of four only two of them, one male and one female, had the required qualifications for the task. They had to give task to the sub-ordinates which were of two types: unrewarding and dull and rewarding and challenging. These tasks were given to the subordinates in one of the two ways, verbally or through written memo. In the scenario, description about the two sub ordinates regarding their qualifications and experience were given in two separate paragraphs, both were worded differently but both the employees had equal competencies. The participants had to select one employee for the task on a 7 point scale. Also participants had to give reason for selecting that employee by filling out questionnaire based on two theories, exchange theory and stereotyping theory. The male participant in the study favored male employee for the challenging task, and the female participants in the study favored female employee for the challenging task-females and for the dull task the results were opposite as male participant selected female employee and female participants selected male employee. Hence, according to Mai-Dalton and Sullivan(1981) there was a possible change in the trend of sex discrimination, because men and women preferred the same sex for the challenging job because they might look forward to a more rewarding relationship with the same sex subordinates.

\section{Methodology}

The banking sector of Pakistan is the targeted segment. Branch managers of banks and their subordinates are the participants. Convenient sampling technique is used to select the sample. The sample size consists of 100 branches of banks in Karachi. Ten banks are taken and ten branches of each bank are taken. The data is collected from Branch Manager of each branch 
and from 4 subordinates of each manager which sum up to 400 subordinate and 100 mangers. Convenience sampling technique is used this study. The primary data is collected through questionnaire which is designed on the basis of earlier researches done in the same area. The questionnaire consists of items related to four tasks; two challenging task and two dull task. The questionnaire was filled by branch manager. The manager was presented one task at a time and was asked to assign that task to any one of the subordinates and then had to fill the questionnaire regarding that subordinate. Likewise the manager had to assign all four activities to the four subordinates and filled the questionnaire for those subordinates. In the end the demographic data from those four subordinates were taken.

The instrument used for this study is a self administered questionnaire filled by managers. The questionnaire first includes the demographics and personality traits provided by the manager. The manager is presented with four tasks, each of which they have to assign to one of their subordinates. Out of four tasks, two tasks are challenging task and two are dull tasks but the managers are not provided with the information as to which one is challenging or dull. In the questionnaire task number one and four are challenging and task number two and three are dull. After assigning a task to a subordinate, the manager filled out eight items for that subordinate and repeated the process for the other three subordinate. These eight items collectively are based on the theoretical concept of exchange and stereotyping theory. These items are scored on a likert type format (with $1=$ Strongly Disagree and $5=$ Strongly Agree). After that the demographics and personality traits of subordinates were taken. MaiDalton's \& Sullivan's (1981) instrument was used in this study majorly.

\section{Research Hypotheses}

H1: Male Managers assign challenging task to male employee.

H2: Male Managers assign challenging task to female employee.

H3: Female Managers assign challenging task to male employee.

H4: Female Managers assign challenging task to female employee.

\section{Results}

The value of Cronbach's alpha for reliability of the questionnaire is 0.761 . The Logistic Regression model is used to analyze the data. The dependent variable is "type of task". It has two levels, challenging task coded as 1 , and dull task coded as 0 . The model initially includes seventeen main effects variable and thirty six 2-way interactions of categorical variables. The model is run multiple numbers of times till all the insignificant variables $(p>0.05)$ are eliminated from the model but with the exception of two main effect variables i.e. gender of manger and gender of subordinate having significant value of .241 and .139 respectively. These two variables are kept in the model because interactions of these variables are significant.

The final model includes eight variables i.e. marital status of the manger, gender of the manager, gender of the sub ordinate, age of the manager, age of the subordinate, years of experience in the same organization of sub ordinate, stereotype, exchange, and two 2-way interactions i.e. gender of manager with gender of sub ordinate and marital status of manger with gender of sub ordinate.

Male manager has less probability to assign a challenging task to male sub-ordinate with odds of $(\exp (B)=0.041, p-$ value $=0.012)$ to 1 , and odd of $(\exp (B)=24.390$, $p-$ value $=0.012$ ) to 1 to a female sub-ordinate. Male subordinate has higher probability of a challenging task to be assigned with odds of $(\exp (B)=4.878, p-$ value $=0.040)$ against 1 only, if manager is a single male. The higher aged sub-ordinate has lesser chances of a challenging task to be assigned as compared to young sub-ordinates with odds of $(\exp (B)=0.666, p-$ value $=0.000)$ against 1 , which means that as the age of the sub- 
ordinate increase, the probability of a challenging task to be assigned decreases. This concludes that managers prefer young sub-ordinates to assign a challenging task. Experienced sub-ordinates have higher chances of a challenging task to be assigned with odds of $(\exp (B)=1.474, p-$ value $=0.003)$ against 1 . The years of experience in the current organization in which subordinate is working, had a positive relationship which shows that as the subordinate gained more experience in the same organization, the probability to receive challenging task also increased. The stereotyping theory with odds of $(\exp (B)=0.375, p-$ value $=0.000)$ and exchange theory with odds of $(\exp (B)=0.076, p-$ value $=0.000)$, both have less than one odds for challenging task against the dull task, which means the more the manager believed in these two theories, the less they are inclined to challenging task.

\begin{tabular}{|c|c|c|c|c|}
\hline Source & Wald Chi-Square & & $\mathrm{df}$ & Sig. \\
\hline Gen_Manager & 1.374 & & 1 & .241 \\
\hline Mar_Manager & 4.973 & & 1 & .026 \\
\hline Gender_Sub & 2.188 & & 1 & .139 \\
\hline Age & 6.615 & & 1 & .010 \\
\hline Age_Sub & 62.090 & & 1 & .000 \\
\hline Yrs_org_Sub & 8.774 & & 1 & .003 \\
\hline Stereotype & 12.211 & & 1 & .000 \\
\hline Exchange & 40.508 & & 1 & .000 \\
\hline Gen_Manager * Gender_Sub & 6.295 & & 1 & .012 \\
\hline Mar_Manager * Gender_Sub & 4.220 & & 1 & .040 \\
\hline \multicolumn{5}{|l|}{ Table 2: Parameter Estimates } \\
\hline Parameters & Wald Chi-Square & $\overline{\mathrm{df}}$ & Sig. & $\operatorname{Exp}(B)$ \\
\hline [Gen_Manager $=1]$ & 71.172 & 1 & .000 & $2.354 \mathrm{E} 10$ \\
\hline [Gen_Manager=2] & 55.538 & 1 & .000 & $2.287 \mathrm{E} 9$ \\
\hline [Mar_Manager=1] & 5.809 & 1 & .016 & .192 \\
\hline [Mar_Manager=2] & · & . & . & 1 \\
\hline [Gender_Sub=1] & 2.036 & 1 & .154 & 5.728 \\
\hline [Gender_Sub=2] & . & . & . & 1 \\
\hline Age & 6.615 & 1 & .010 & 1.099 \\
\hline Age_Sub & 62.090 & 1 & .000 & .666 \\
\hline Yrs_org_Sub & 8.774 & 1 & .003 & 1.474 \\
\hline Stereotype & 12.211 & 1 & .000 & .375 \\
\hline Exchange & 40.508 & 1 & .000 & .076 \\
\hline$[$ Gen_Manager $=1] *[$ Gender_Sub $=1]$ & 6.295 & 1 & .012 & .041 \\
\hline$[$ Gen_Manager $=1] *[$ Gender_Sub $=2]$ & $\cdot$ & . & . & 1 \\
\hline$[$ Gen_Manager $=2] *[$ Gender_Sub $=1]$ & . & . & . & 1 \\
\hline$[$ Gen_Manager $=2] *[$ Gender_Sub=2] & . & . & . & 1 \\
\hline$[$ Mar_Manager $=1] *[$ Gender_Sub $=1]$ & 4.220 & 1 & .040 & 4.878 \\
\hline$[$ Mar_Manager $=1] *[$ Gender_Sub=2] & . & . & . & 1 \\
\hline$[$ Mar_Manager $=2] *[$ Gender_Sub $=1]$ & . & . & . & 1 \\
\hline$[$ Mar_Manager $=2] *[$ Gender_Sub=2] & . & . & . & 1 \\
\hline
\end{tabular}


The male managers did not prefer the male subordinates for challenging task as a result $\mathrm{H} 1$ was rejected. The male managers preferred female subordinates for the challenging task, so $\mathrm{H} 2$ is accepted. Female managers don't prefer any gender to assign challenging task as a result $\mathrm{H} 3$ and $\mathrm{H} 4$ are rejected.

\section{Discussion}

It is concluded in many previous researches that the managers support the subordinates of same gender in assigning tasks that are challenging and rewarding and for the assignment of dull or unrewarding tasks, subordinates of opposite gender are selected (Mai-Dalton \& Sullivan, 1981; Rosen \& Jerdee, 1978; Taylor \& Ilgen, 1981). According to exchange theory, employees are selected of the same gender for the challenging job for the reason that managers looked forward to a more rewarding relationship with those employees and because there are less chances of conflict during the work with the employees of same gender (MaiDalton \& Sullivan, 1981). The outcome of this study show contradictory results, as male managers are more inclined to female in assigning the challenging task. However, young male managers are inclined to male subordinates in assigning challenging task. One of the explanations for the results of the present study can be that male mangers prefer the female subordinate as to avoid accusation of sex discrimination.

The results of this study can be considered as encouraging and discouraging as well. The encouraging aspect is that the women are also chosen for challenging task especially by married male manager. This depicts that after getting the experience of living and working with women, closely observing women, managers might overcome the stereotyping problem of associating women to tasks that are of low level and dull as contrast to task that are challenging and rewarding. Moreover, in Pakistan, working women are very much committed and capable. If a manager is emotionally intelligent and can perceive the real hidden talent in a female sub-ordinate, then he will surely assign challenging task to her. Previous researches have also conclude that when men works with capable women, the chances stereotyping reduces (Taylor \& Ilgen, 1981). The discouraging aspect is that organization may not be using the full potential of highly capable male employees, if male managers are inclined towards the female sub-ordinates in assigning the challenging tasks. The possibility of reverse discrimination is highly probable is such situations.

According to exchange theory, managers select employees of the same gender for the challenging job for the reason that managers look forward to a more rewarding relationship with those employees and there are less chances of conflict during the work with the employees of same gender (Mai-Dalton \& Sullivan, 1981). The exchange theory is valid in the beginning of the career for male managers but for experience managers the results of this study are opposite to exchange theory.

It is very essential for any organization to check the presence of any kind of discrimination. Every organization should make adequate efforts to monitor that the tasks are assigned according to the competence of each individual rather than just considering the gender of the employee. One of the ways to achieve such transparency in assigning tasks is with the help of human relations training as this would help individuals of both the genders to feel comfortable while working with each other, to gain trust on the capabilities of each other, and to avoid doing gender discrimination on the basis of stereotyping.

Percentage of women entering into practical fields has increased. Women are now focusing on acquiring higher education and willing to work. Women have developed the need for achievement and power which was previously assumed to be the characteristic of men only. The role of women is changing in society now and women are also contributing on equal means with men in providing financial stability to the family. With such a transition of 
role, the traditional concepts of stereotyping should be revised in which male are considered most suitable for jobs.

An extension of this research may be to make use of a situation based role and get significant differences between male mangers and female managers in terms of assigning tasks in different ways. Significant data from all the subordinates under the span of a manger can also be taken in order to assess the presence of gender or any other type of discrimination besides just taking the data from the subordinates which are assigned tasks. Another further enhancement of the present study can make use of design measures that are repetitive. In such a case, each manger would be given two or more scenarios, and each will explain challenging and dull tasks of different types and this information will be made available to mangers as to which task is challenging or dull. This study will assist in analyzing any significant difference of results as compared to present research.

Future research can also focus on the discrimination against females in other conventionally male occupations. On the other hand, another vital research need to be done to investigate the impact of extremely visible, well recognized successful women on the career opportunities of other women within an organization as this would help in analyzing any possibility of reduction of gender discrimination by the presence of such women.

\section{Declarations}

\section{Competing Interests}

The authors declare that they have no competing interests.

\section{Authors' Contribution}

The manuscript has been extracted out of the master's thesis by Rashid, N. and has been completely supervised by Samim, B. A.

\section{References}

Barclay, L. (1982). Social Learning Theory: A Framework for Discrimination Research. Academy of Management Review, 7(4), 587-594.

Bartol, K.M. (1980). Female managers and quality of working life: The impact of sex-role stereotypes. Journal of Occupational Behaviour, 205-221.

Berlew, D.E., \& Hall, D.T. (1966). The socialization of managers: Effects of expectations on performance. Administrative Science Quarterly, 207-223.

Haberfeld, Y. (1992). Employment discrimination: An organizational model. Academy of Management Journal, 35(1), 161-180.

Heilman, M.E. (1997). Sex discrimination and affirmative action remedy: The role of sex stereotypes. Journal of Business Ethics, 16(9), 877-889.

Igbaria, M., \& Baroudi, J.J. (1995). The impact of job performance evaluations on career advancement prospects: An examination of gender differences in the IS workplace. MIS Quarterly, 107-123.

Lane, N., \& Crane, A. (2002). Revisiting gender role stereotyping in the sales profession. Journal of Business Ethics, 40(2), 121-132.

Lehmijoki, U., \& Palokangas. (2006). Population growth overshooting and Trade in developing countries. Dynamics, Economic Growth and International Trade Conference papers, c011_025.

Mai-Dalton, R.R., \& Sullivan, J.J. (1981). The effects of Manager's sex on the assignment to a challenging or a dull task and reasons for the choice. Academy of Management Journal, 24(3), 603-612. 
Ngo, H.-y., Foley, S., Wong, A., \& Loi, R. (2003). Who gets more of the pie? Predictors of perceived gender inequity at work. Journal of Business Ethics, 45(3), 227-241.

Rosen, B., \& Jerdee, T. H. (1978). Perceived sex differences in managerially relevant characteristics. Sex Roles, 4(6), 837-843.

Renwick, P.A., \& Tosi, H. (1978). The effects of sex, marital status, and educational background on selection decisions. Academy of Management Journal, 21(1), 93-103.

Schein, V.E., Muller, R., Lituchy, T., \& Liu, J. (1996). Think manager-think male: a global phenomenon? Journal of Organizational Behavior, 17(1), 33-41.

Szwajkowski, E., \& Larwood, L. (1991). Rational decision processes and sex discrimination: Testing 'rational' bias theory. Journal of Organizational Behavior, 12(6), 507-527.

Taylor, M. S., \& Ilgen, D. R. (1981). Sex discrimination against women in initial placement decisions: A laboratory investigation. Academy of Management Journal, 24(4), 859865. 